\title{
Quantitative Analysis of the Relationship Between Maxillary Incisors and the Incisive Canal by Cone-Beam Computed Tomography in an Adult Population of Mangaluru
}

\author{
D. Vaishnavi", V Harshitha, Kumar Kishore \\ Department of Orthodontics, University of A J Institute of Dental Sciences, Mangaluru, India
}

\begin{abstract}
Objective: Maxillary anterior teeth play a role in the aesthetics, phonetics, and mastication. For successful orthodontic treatment evaluating the morphology of the alveolar bone and incisive canal would help in avoiding root resorption, dehiscence, and fenestration. This study is aimed to research the configurational relationships among maxillary incisors, alveolar bone, and incisive canal through Cone Beam Computerated Tomography(CBCT).
\end{abstract}

Materials and methods: CBCT images of 35 orthodontic patients were for length of the canal(L); angles palatal plane and the maxillary alveolar border( $\theta 1)$, the incisive canal( $(\theta 2)$, and maxillary incisor( $\theta 3)$; distance from the right maxillary incisor to the incisive canal(D). All the measurements were performed on sagittal plane with the exception of (D) which was made on axial plane. Statistical analysis was performed on the above parameters using two sample test and Pearson's correlation analysis.

Result: There was no statistically significant difference between males and females for all the variables although there large interindividual variation. There was a positive moderate correlation between $\theta 1$ and $\theta 2(0.480), \theta 1$ and $\theta 3$ (0.487), $\theta 2$ and $\theta 3(0.345)$. The mean value for $L$ and $D$ were $10.38 \mathrm{~mm}$ and $4.14 \mathrm{~mm}$ respectively.

Conclusion: There exists large interindividual variability for canal, proximity of incisors with that incisive canal which could not be precisely predicted by the conventional cephalograms. The results of the study could be helpful clinically in planning orthodontic treatment for significant intrusion and retraction of maxillary incisors.

Keywords : Maxillary incisors; Incisive canal; Tomography

\section{INTRODUCTION}

While not specifically in the Hippocratic Oath, primum non nocere is believed to be derived from it and means first, do no harm or above all else, do no harm. In other words, before you do anything to a patient, make sure that you are not making matters worse. What good does it do to straighten teeth if in doing so you cause the patient to lose them?[1].With regard to maxillary incisor movement, Ackerman et al. presented the concept of "envelope of discrepancy", which describes the limitations of the range of orthodontic movement of the maxillary incisor [2]. Contact with hard tissue structures, such as the labial, palatal, or incisive canal cortical plates, is a risk factor for apical root resorption in the maxillary incisor, and it is one of the iatrogenic complications of orthodontic treatment. The incisive canal is an anatomic structure that runs posterior and more close to the roots of the central incisors in the median plane of the palatine process of the maxilla, surrounded by thick

Correspondence to: Vaishnavi D, Department of Orthodontics, University of A J Institute of Dental Sciences, Mangaluru, India,Tel:91 87622 82484; E-mail: dvaishnavi85@gmail.com

Received date: June 01, 2021; Accepted date: June 15, 2021; Published date: June 22, 2021

Citation: Vaishnavi D, Harshitha V, Kishore K (2021) Quantitative Analysis of the Relationship Between Maxillary Incisors and the Incisive Canal by Cone-Beam Computed Tomography in an Adult Population of Mangaluru. Dentistry. Vol.11 Iss.7 No:138.

Copyright: ( 2021 Vaishnavi D, et al. This is an open-access article distributed under the terms of the Creative Commons Attribution License, which permits unrestricted use, distribution, and reproduction in any medium, provided the original author and source are credited. 
cortical bone. It connects the floor of the nasal cavity with the palate and opens into the oral cavity as incisive foramen. It runs parallel to the maxillary central incisors and transmits nasopalatine vessels and nerves, branches of the maxillary division of the trigeminal nerve, and the maxillary artery. Because of proximity of incisive canal to the maxillary incisors, the surgical invasion and its complications of the incisive canal during dental procedures in maxillary incisor region can cause nonosseointegration of dental implants or sensory dysfunction. The precise location of incisive canal in reference to the maxillary incisors isn't well documented within the orthodontic literature due to the difficulties in detecting incisive canal morphology using conventional twodimensional radiographs [3].

The objective of this study was to evaluate the morphologic features and the relationship between roots of maxillary incisors and the incisive canal using Cone Beam Computed Tomography (CBCT) [4].

\section{MATERIALS AND METHODS}

The study was carried out on the patients visiting the out-patient section of the Department of Orthodontics and Dentofacial Orthopaedics, AJ Institute of dental sciences, Mangaluru.CBCT scans were taken for those who required CBCT for diagnosis and treatment planning. The inclusion criteria include patients having lateral cephalogram, normal anteroposterior skeletal relationship (ANB of $0^{\circ}-4^{\circ}$ ), normal overjet and overbite with Class I molar relationship. The exclusion criteria were history of orthodontic treatment, missing or supernumerary maxillary incisors, prosthesis in relation to maxillary incisors, history of trauma to maxillary incisors, and congenital anomalies like cleft lip and palate. Based on the inclusion and exclusion criteria, 35 subjects were selected [5].

The data was obtained using NewTom GiANO NNT Scanner with the patient in upright position and head positioned along the Frankfort horizontal plane, running parallel to the floor. All the scans were taken using the same machine by the same operator. The operating parameters were set at $3 \mathrm{~mA}$ and $90 \mathrm{kV}$, dose of $80-100 \mu \mathrm{Sv}$ and the scan time of 9 seconds. All CBCT images were taken using a large dentoalveolar field of view. It was determined that the sagittal plane was perpendicular to the axial plane and parallel to the plane passing through anterior nasal spine and posterior nasal spine (Figures 1 and 2) [6].

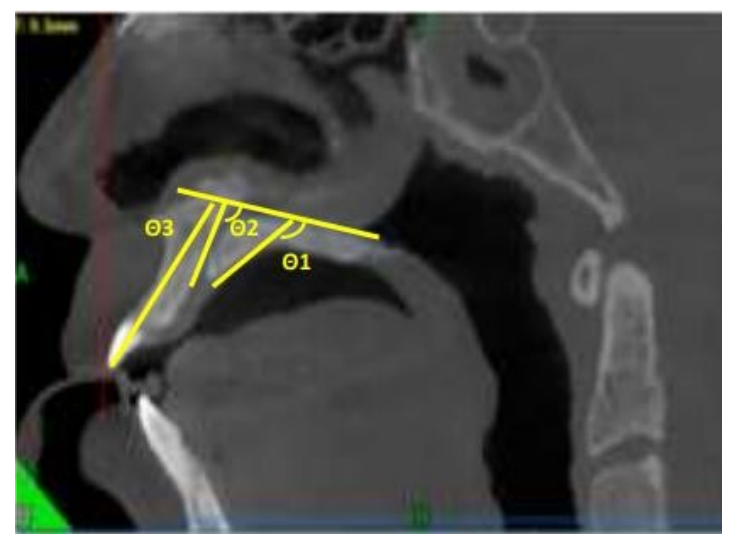

Figure 1: CBCT images of 35 orthodontic patients were evaluated for the following measurements.

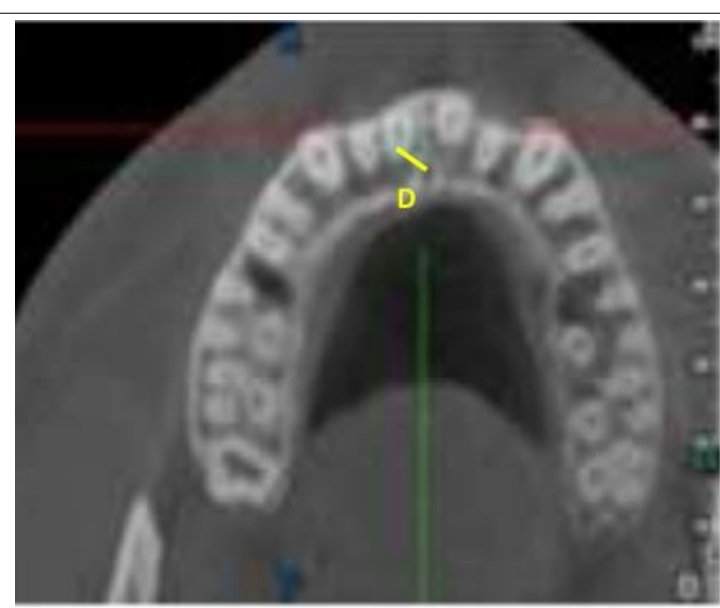

Figure 2: CBCT images of 35 orthodontic patients were evaluated for the following measurements.

Length of the canal(L).

Angles between the palatal plane and the maxillary alveolar border $(\theta 1)$.

The incisive canal $(\theta 2)$ the maxillary incisor $(\theta 3)$.

Distance from the right maxillary incisor to the incisive canal(D)

\section{RESULTS}

\begin{tabular}{lll}
\hline & Mean & Std. deviation \\
\hline Theta1 & 136.388 & 7.86421 \\
\hline Theta2 & 108.105 & 10.81246 \\
\hline Theta3 & 114.666 & 10.43686 \\
\hline $\begin{array}{l}\text { Length of incisive } \\
\text { canal }\end{array}$ & 10.3857 & 3.11015 \\
\hline $\begin{array}{l}\text { distance of the right } \\
\text { maxillary incisor to } \\
\text { the incisive canal }\end{array}$ & 0.1486581 \\
\hline
\end{tabular}

Table 1: Mean values of the variables drescriptive statistics.

\begin{tabular}{lll}
\hline & $\begin{array}{l}\text { Correlation } \\
\text { coefficient }\end{array}$ & 'p' value \\
\hline $\begin{array}{ll}\text { Theta } 1 \text { vs. } \\
\text { theta } 2\end{array}$ & 0.480 & 0.004 \\
\hline Theta 1 vs. & 0.487 & 0.003 \\
theta 3 & & \\
\hline Theta 2 vs. & 0.345 & 0.043 \\
theta 3 & &
\end{tabular}

Table 2: Pearson's correlation test. 
Correlation between theta 1 and theta 2 is highly statistically significant $(\mathrm{p}=0.004)$. There is a positive moderate correlation between theta 1 and theta $2(0.480)$.

Correlation between theta 1 and theta 3 is highly statistically significant $(\mathrm{p}=0.003)$. There is a positive moderate correlation between theta 1 and theta $3(0.487)$.

Correlation between theta 2 and theta 3 is statistically significant $(\mathrm{p}=0.043)$. There is a positive moderate correlation between theta 2 and theta $3(0.345)$.

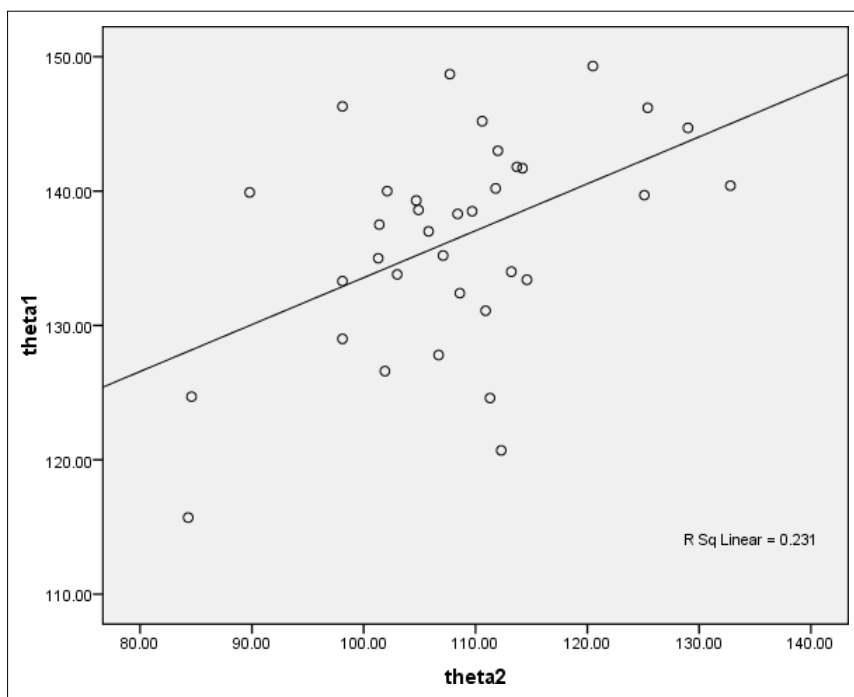

Figure 3: Scatter plot for Theta 1 vs. Theta 2.

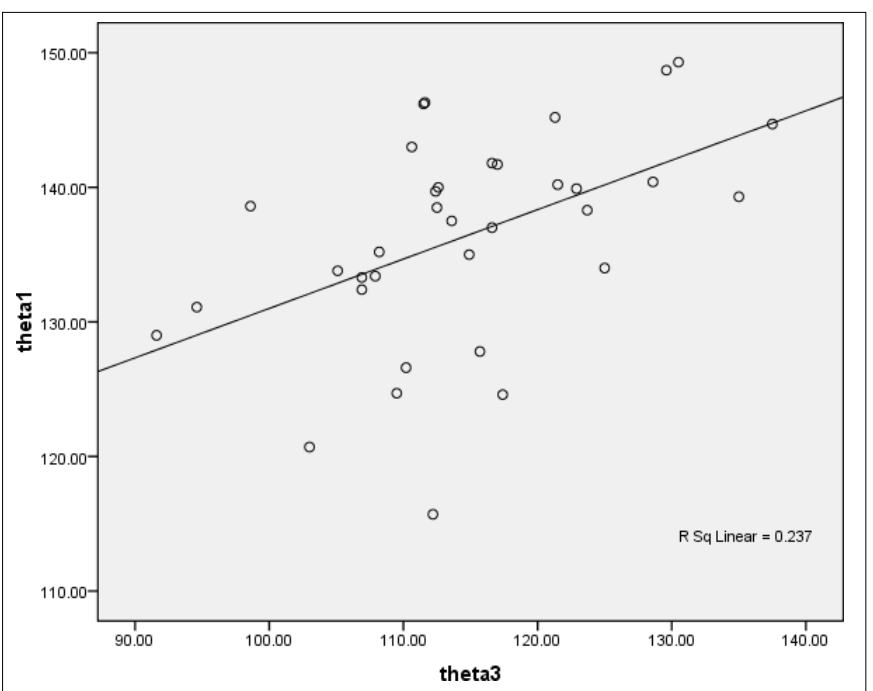

Figure 4: Scatter plot for Theta 1 vs. Theta 3.

There is a positive moderate correlation between $\theta 1$ and $\theta 2(0.480), \theta 1$ and $\theta 3$ (0.487), $\theta 2$ and $\theta 3(0.345)$.

The mean value for $L$ and $D$ are $10.38 \mathrm{~mm}$ and $4.14 \mathrm{~mm}$ respectively.

There are large interindividual variation although there were no significant differences between males and females.

\section{DISCUSSION}

This is the first study involving the Mangaluru population to investigate the anatomical characteristics of maxillary incisors, the incisive canal, and the maxillary alveolar border using CBCT images [7].

Inclination of maxillary incisors is significantly correlated with those of the maxillary alveolar border and axis of the incisive canal [8].

First, in the present study, the length of the incisive canal in male patients is similar to that in female patients, which is discordant with the findings of a previous study [9].

The FOV of CBCT images in the present study is larger in comparison with those reported in previous studies [10].

The average anterior-posterior distance between the maxillary central incisor roots and the incisive canal measured is 4.14 which is lesser than previous studies. This $4.14 \mathrm{~mm}$ distance does not necessarily imply the "safety zone" for retraction because individuals with relatively large interroot distances are not at risk of canal invasion or contact even following maximum retraction. However, a large diversity in anatomy, morphology and size of the incisive canal and incisive foramen in different people are frequently reported with three-dimensional evaluation. The incisive canal, in many circumstances, is deviated toward the right central incisor.

Because of the proximity of maxillary incisors to incisive canal, the possibility of sensory dysfunction in the anterior region and failure of osseointegration has been reported in cases of contact of the incisive canal through surgical interventions such as dental implant placement.

\section{CONCLUSION}

This study has the proximity between incisive canal and maxillary central measured at 4.14 which is quite less indicating the closeness of incisor root to the canal which would aid us in carrying out the orthodontic procedures effectively.

This study demonstrated that the incisive canal had large interindividual variability, and the proximity between the incisive canal and the incisal root could not be precisely predicted by the conventional cephalogram.

\section{REFERENCES}

1. Morneau J.How to prevent root resorption using the golden rule of orthodontics.Dentistry iq.2006.

2. Sarver DM. The importance of incisor positioning in the esthetic smile: the smile arc. Am J Orthod Dentofac Orthop. 2001;120(8):98111.

3. Arnett GW, Bergman RT. Facial keys to orthodontic diagnosis and treatment planning. Part I. Am J Orthod. 1993;103(4):299-312.

4. Kokich V. Esthetics and anterior tooth position: an orthodontic perspective part III: mediolateral relationships. J Esthet Restor Dent. 1993;5(5):200-207.

5. Chung CJ, Choi YJ, Kim KH. Approximation and contact of the maxillary central incisor roots with the incisive canal after maximum retraction with temporary anchorage devices: report of two cases. Am J Orthod Dentofac Orthop. 2015;148:493-502.

6. Proffit W, Fields H, Sarver D. Contemporary orthodontics. 5th ed. St Louis: Elsevier; 2013. 
7. Handelman CS. The anterior alveolus: its importance in limiting orthodontic treatment and its influence on the occurrence of iatrogenic sequelae. Angle Orthod. 1996(2);66:95-109.

8. Tian YL, Liu F, Sun HJ, Lv P, Cao YM, Yu M, et al. Alveolar bone thickness around maxillary central incisors of different inclination assessed with cone-beam computed tomography. Korean J Orthod. 2015;45:245-52.
9. Mraiwa N, Jacobs R, Van Cleynenbreugel J, Sanderink G, Schutyser F, Suetens $\mathrm{P}$, et al. The nasopalatine canal revisited using 2D and 3D CT imaging. Dentomaxillofac Radiol 2004;33(6):396-402.

10. Liang X, Jacobs R, Martens W, Hu Y, Adriaensens P, Quirynen M, et al. Macro- and micro- anatomical, histological and computed tomography scan characterization of the nasopalatine canal. J Clin Periodontol. 2009;36:598-603. 